with the Warwickshire constabulary, probation service, and road safety unit.

Finally, we strongly support Coventry's proposals for the introduction of random breath testing in Britain. There is now substantial evidence from Australia, New Zealand, Finland, and the United States that this measure is effective in reducing drinking and driving. ${ }^{2}$ This initiative is also actively supported by the Parliamentary Advisory Council on Transport Safety, the Campaign Against Drinking and Driving, and Action on Drinking and Driving. The case for reducing the legal limit is not quite so convincing at present, although this too is actively supported by the Campaign Against Drinking and Driving and is being given careful consideration by the Parliamentary Advisory Council on Transport Safety.

GORDON AVERY JOANNA WATSON

South Warwickshire Health Authority, Warwick CV34 4DE

1 Department of Transport. Road accidents Great Britain 1984. London: HMSO, 1985:26.

2 Parliamentary Advisory Council on Transport Safety. Drinking and driving - the case for random breath testing. Road Traffic Law Bulletin 1987;4(5):33-8.

\section{AIDS and the lung}

SIR,-The view expressed by Dr Ann Millar (23 May, p 1334) that Mycobacterium xenopi and $M$ kansasii are more commonly found than mycobacterium of the $M$ avium-intracellulare-scrofulaceum group is not the experience of this reference unit, which receives strains from all over Britain.

Table I shows that this group of mycobacteria are the most frequently isolated opportunist mycobacteria from all types of specimen and particularly pulmonary specimens. In many patients there is disseminated disease and the same strain can be isolated from a variety of sites. The amount of information available to the reference unit about these patients is limited. For example, request forms may be labelled "AIDS patient" or "HIV positive patient," and we do not know if the patients have in fact developed the full blown syndrome.

Table II gives some indication of the extent to which the acquired immune deficiency syndrome (AIDS) contributed to the incidence of opportunist mycobacterial infections in England and Wales in 1986. Infections with the $M$ avium-

TABLE I-Primary site of isolation of opportunist mycobacteria from patients positive for $H I V$

Bone

Pulmonary^ Faeces marrow Other

\begin{tabular}{lrrrr}
\hline $\begin{array}{l}M \text { avium-intracellulare- } \\
\text { scrofulaceum group }\end{array}$ & 16 & 13 & 6 & 4 \\
$M$ kansasii & 5 & - & - & 1 \\
$M$ xenopi & 2 & - & - & - \\
$M$ malmoense & 1 & - & - & -
\end{tabular}

^Includes sputum, bronchial washings, and bronchial biopsy.

TABLE II-Infections due to opportunist mycobacteria in England and Wales in 1986*

\begin{tabular}{lccc}
\hline & $\begin{array}{c}\text { Not HIV } \\
\text { positive }\end{array}$ & $\begin{array}{c}\text { HIV } \\
\text { positive }\end{array}$ & Total \\
\hline$M$ kansasii & 63 & 6 & 69 \\
$M$ avium-intracellulare- & & & \\
scrofulacerm group & 33 & 39 & 72 \\
$M$ xenopi & 38 & 2 & 40 \\
$M$ malmoense & 33 & 1 & 34
\end{tabular}

ॠExcludes children with cervical adenopathy and patients with skin lesions. intracellulare-scrofulaceum group in patients positive for the human immunodeficiency virus (HIV) outnumbered those in the normal population, and for the first time, as far as we know, this group was the most common opportunist mycobacterial pathogen. In previous years there have always been nearly twice as many infections with $M$ kansasii as with the other species or groups.

There is no obvious reason why this group should be more prevalent in HIV positive patients. All opportunist mycobacteria are present in the environment, and exposure cannot be avoided. $M$ xenopi and $M$ kansasii have been isolated from water supplies in London, ${ }^{1}$ and most infections with $M$ xenopi occur in the London area. ${ }^{2} M$ malmoense infections have increased from an average of one or two a year before 1980 to 33 in 1986. Despite this, in common with the American experience, it is the $M$ avium-intracellulare-scrofulaceum group that most frequently infects patients with AIDS. It would be interesting to know why.

Public Health Laboratory Service,

P A JENKINS

Cardiff CF4 4XW

1 McSwiggan DA, Collins $\mathrm{CH}$. The isolation of $\mathrm{M}$ kansasii and $M$ xenopi from water systems. Tubercle 1974;55:291-7.

2 Marks J, Jenkins PA. The opportunist mycobacteria-a 20 year retrospect. Postgrad Med f 1971;47:705-9.

AUTHOR'S REPLY - The information presented by Dr Jenkins from the Cardiff Reference Laboratory is most interesting. Atypical mycobacteria from the Middlesex Hospital are sent to the Dulwich Reference Laboratory. Until December 1986 four cases of atypical mycobacteria had been isolated from the lungs of patients with AIDS, and all were of the $M$ xenopi strain. The published clinically based British data come from the St Mary's group In 1985 three atypical cases were reported, two of the $M$ xenopi and one of the $M$ kansasii strain. More recently, 13 cases of atypical mycobacteria in patients with AIDS were reported, of which seven were in the lung. ${ }^{2}$ Precise figures for the seven cases of mycobacteria in the lung were not given, but the 13 consisted of five $M$ avium, five $M$ xenopi, one $M$ flavescens, and three untyped.

The other hospital in London dealing with large numbers of cases of AIDS is St Stephen's, where very few cases of atypical mycobacteria have been found in the lung and those that have were $M$ avium-intracellulare (unpublished observations).

The difference between these clinical impressions and those of the Cardiff Reference Laboratory may partly be due to the point touched on by Dr Jenkins, that the information given to the reference laboratory by the clinicians is limited.

Middlesex Hospital Medical School and

ANN B Millar

University College London,

London WIN 8AA

1 Warren JB, Shaw RJ, Weber JN, et al. Role of fibreoptic bronchoscopy in management of pneumonia in acquired immune deficiency syndrome. $\mathrm{Br}$ Med $\mathcal{F} 1985 ; 291: 1012-3$.

2 Shaw RJ, Rowland-Hill CA, Parkin J, et al. Pulmonary complications of AIDS: a review of 90 English cases. Thorax 1986;41:730.

\section{Intravenous digital subtraction angiography}

SIR,-I I was disappointed that neither Dr Peter Sandercock (30 May, p 1368) nor Dr W J Windebank (p 1369) mentioned an important advance in vascular imaging - namely, intravenous digital subtraction angiography. With this technique contrast medium may be injected intravenously (either into an antecubital vein or into a central vein) and subtracted images of the arterial system in the area of interest may be obtained. With attention to detail and good radiographic technique images of very high quality may be obtained, without the risks of arterial and selective catheterisation techniques.

In patients with carotid stenosis this technique may be performed as an outpatient procedure, and combined with Doppler ultrasound it provides a safe and accurate means of assessing the extracranial cerebral vessels. Since the installation of our digital subtraction angiography unit (Philips) in 1984 we have performed 1939 vascular studies in all areas of the body. Of these, 556 have been intravenous digital subtraction angiography studies, 146 to examine the extracranial cerebral vessels ( 292 carotid bifurcations). There have been no neurological complications or noteworthy nonneurological complications in this group. Digital subtraction angiography units are being installed in many radiology departments, and skill in the use of duplex Doppler ultrasound is increasing.

The availability of these two methods makes it possible, for the first time, safely to study the extracranial vessels and lower the threshold for investigation in patients with asymptomatic carotid bruits. ${ }^{12}$ Dr Windebank comments that pulmonary arteriography is the gold standard for diagnosing pulmonary thromboembolism and that the investigation is under used. This is related to several factors-not only the fact that injecting large volumes of contrast medium into the pulmonary vessels may be hazardous but also that the investigation may be difficult to arrange and requires considerable radiological skill for its execution and accurate interpretation.

Intravenous digital subtraction angiography seems to be better tolerated by patients and avoids the risk of catheterising the femoral veins and possibly dislodging further emboli and of transcardiac catheterisation, and, although expert interpretation is still required, the technique is much simpler to perform, takes less time, and is also cheaper than pulmonary arteriography. ${ }^{34}$ Digital subtraction angiography examinations have been reported to be diagnostic in between $93 \%$ and $98 \%$ of patients examined. ${ }^{45}$

ANNE P Hemingway

Department of Diagnostic Radiology,

Royal Postgraduate Medical School,

London W12 0HS

1 Wood GW, Lukus RR, Tomsick THA, Chambers AA. Digital subtraction angiography with intravenous injections: asses ment of 1000 carotid bifurcations. AFR 1983;140:855-9.

2 D'Alotto C, Pelz DM, Rankin RN. A comparison of angiography, intravenous digital subtraction angiography and duplex ultrasound in the diagnosis of carotid artery atherosclerosis. 7 Can Assoc Radiol 1985;36:200-8.

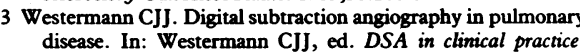
Holland: Philips Medical Systems, 1986:143-54.

4 Pond GD, Oritt ThW, Capp M. Comparison of conventional pulmonary angiography with intravenous digital subtraction angiography for pulmonary embolic disease. Radiology 1983 147:345-50.

5 Bjork L. Digital angiography in pulmonary embolism. Acto Radiologica Diagnostica 1986;27:179-81.

\section{Measles: Who pays the cost?}

SIR,-The policies adopted in Dr Adrian Hastings's practice must surely help to increase the uptake of measles vaccination (13 June, $p$ 1527). Additional measures, however, such as those used in this surgery may help, as we have a $100 \%$ measles vaccination coverage for children born in 1982-4 inclusive. The Greater Glasgow Health Board computer immunisation recall system has played a major part in this achievement. Dr Hastings finds his local system a victim of its own efficiency, but it can be harnessed to the general practitioner's own ends. 